\title{
Vocational Training of Russian Students within Educational Cluster
}

\author{
Rais S. Safin ${ }^{1} \&$ Evgeny A. Korchagin ${ }^{1}$ \\ ${ }^{1}$ Kazan State University of Architecture and Engineering, Kazan, Russia \\ Correspondence: Rais Semigullovich Safin, Kazan State University of Architecture and Engineering, Zelenaya \\ Street 1, Kazan, Tatarstan, 420043, Russia. E-mail: safin@kgasu.ru
}

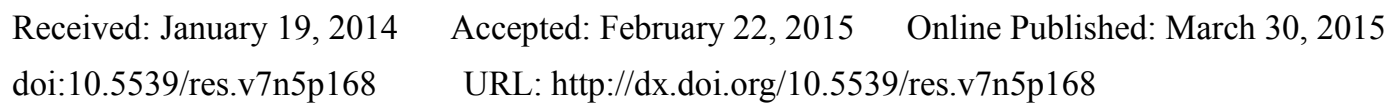

\begin{abstract}
The experience of professional education of Russian students under the conditions of the educational cluster is analyzed. Educational cluster is a relatively new kind of the educational consolidation, united by the industry sector principle, of secondary and tertiary educational institutions, created in order to increase the competitiveness of their graduates. What advantages, in comparison with the conventional education, does cluster education have? What are the features of the cluster-based education? Those are the questions that haunt the majority of the specialists, studying vocational education in Russia. The authors of the article tried to answer these, and relative, questions and in this lies the topicality of the article.

The aim of the creation of the educational clusters are defined. The advantages of cluster-based education in comparison with the conventional education system are revealed. The Kazan State University of Architecture and Engineering -based educational cluster is dealt with in this article. The article says how the cluster influenced the professional training in civil engineering. The change of approach to creation the flexible curricula is shown. The data over six years; concerning; training of relative specialties, training at KNAUF company training center, created under the aegis of Kazan State University of Architecture and Engineering; are given.
\end{abstract}

The article may seem to be useful to scholars, studying vocational training, as well as to future employers, concerned about quality of graduates.

Keywords: vocational training, undergraduates, educational cluster, civil engineering educational cluster, aims of cluster, vocational curriculum, curriculum, educational cluster advantages

\section{Introduction}

The developed countries experience indicates that economy and industry is developed only where highly qualified specialists and education system that trains such specialists are present. The quality of graduates' training must be at the same level as economy and industry. The awareness of this is constantly growing and Russia makes much effort to achieve it. Russian universities are being consolidated. Industry-relative educational institutions are being united. Secondary school curricula are being implemented within universities. Secondary schools are handed over from federal to regional subordination. According to the authors of the education system reform, regional education system should represent a model that supposedly should be fulfilled through public-private partnership between educational institutions and private enterprises. All education levels, within one industry sector, will supposedly be subordinate on the basis of coherent curricula. The curricula will be created with the respect to professional standards developed by future employers. The educational institution staff and private enterprises will cooperate according to "corporatism" principles (Korchagin \& Safin, 2012, 2013; Shaidullina et al., 2015; Masalimova \& Nigmatov, 2015; Ivanenko et al., 2015; Safin et al., 2013; Ajtuganov et al., 2012).

As a result of this reform, being implemented in Russian professional education system for 20 years, educational clusters have been invented. The emergence of the educational clusters was triggered by idea of integration of vocational training and relevant industry within the open market condition. Cluster emulates a "communal apartment" of specialist training which enables Russia to make its economy more competitive. In accordance with the authors' conception an educational cluster is meant to consolidate efforts of industry-relative education institutions with relevant private enterprises into one space. The practical implementation of the educational cluster started owing to the government. It prompted to start the communication between educational institutions 
and private enterprises in order to solve financing problem of the educational institution, to magnify the role of practical training through making it more close to practical activities and production so that the labor resources should be enough. The educational clusters was hopefully to increase vocational training quality so that graduates should be in demand and meet the requirements of employers. This was reflected in the aims that the educational clusters were created for and these are:

- To optimize career counseling at secondary training;

- To encourage the development of lifelong education;

- To increase the competence of graduates;

- To increase private enterprises' competitiveness;

- To implement personality-aimed training process;

- To provide adequate quantity and competence of graduates for private enterprises;

- To increase competence of an employee;

- To provide the development of a branch by means of vocational training;

- To increase the effectiveness of innovation use in education, science and technology;

- To reduce terms of vocational training while going to the next level of training.

The main goal, in turn, lays in the creation of integer system of multilevel education for an industry on the basis of integration of education institution into educational cluster which would: provide the quality of training, training terms optimization, further work of graduates at the enterprises; stimulate the carrying out of problem-aimed, fundamental and applied research; provide the creation of a flexible further education system for employees (Safin et al., 2013; Ministry of Education and Science of the Republic of Tatarstan, 2009).

To some extent, the educational clusters have been created in the majority of Russia's regions. For example in the Republic of Tatarstan 14 educational clusters were created. Those were created on the basis of secondary and tertiary education institutions.

\section{Methodological Framework}

The theoretical and methodological basis for the creation of educational clusters in the Republic of Tatarstan was the idea of the integration of science, education and production that was quite well known, elaborated and insistently implemented at the times of soviet planned economy paradigm. The attractiveness of this idea for a market economy is that the integration of the learning process within educational cluster is linked with its intensification. The fact is that the integration helps to work out curricula, while intensifying of a training process helps to organize the training process. Cooperation, in turn, allows to solve the main contradiction between the amount of information in our days on one hand and limited cognitive abilities of the human being on the other. These aims may be successfully achieved only when student is given the opportunity to check one's knowledge during internship. Therefore, the idea of integrating the science, education and production in the form of combining scientific, industrial and educational institutions in the educational cluster based on their industry sector and geographical proximity, increases the competitiveness of its members. While time; needed to train a competitive specialist-in-demand, work activity adaptation; is considerably reduced that is profitable.

Scientific educational cluster, created at Kazan State University of Architecture and Engineering, which includes along with it 8 educational institutions of civil engineering industry sector, helps us understand how civil engineering educational cluster influenced training process.

One should point out that the creation of the educational cluster should include (Korchagin \& Safin 2012, 2013; Safin et al., 2012):

- Study of staff needs, its qualification in construction industry of the region;

- Dialogue and cooperation with: the Ministry of Construction, Architecture, Housing and Communal Services; construction businesses; state-owned construction firms and organizations; construction materials plants and educational institutions;

- The development of effective mechanisms for cooperation between all members of the education cluster;

- The creation of conditions necessary for the development of the cluster.

\section{Results}

In educational cluster the highest priority is given to universities. The structure of the educational cluster also 
includes educational institutions of secondary vocational education, as a consequence, a student in the cluster has the ability to get any qualifications after each educational level (Korchagin \& Safin 2013; Masalimova et al., 2014; Shaidullina et al., 2014, 2015). Moreover, secondary vocational students have the opportunity to have tertiary education by reduced curriculum by means of the coherent curricula within one educational cluster. Thus, by Kazan State University of Architecture and Engineering curricula, which are coherent to secondary vocational schools curricula, within last 6 years 58 students study 3 rd year, 35 students study the $4^{\text {th }}$ (Fig. 1).

Thus, educational cluster has the potential to solve continuous education problems. Continuous curriculum within the creation of continuous vocational training allows to optimize the formation and development of specialist's vocational training potential during work activity. This significantly expands the possibility of building students' individual learning paths. The consolidation of educational institutions of secondary and higher vocational education in a single cluster can also bring an agreement to the educational standards of various educational levels.

We should point out that the creation of the civil engineering educational cluster has significantly changed the approach to the development of flexible curricula and programs at the university that are largely contributed by the business-community For example, the subjects of professional "series of subjects" include theoretical and practical training material, needed for the development of specific areas of professional activity, and content of subjects in this "series of subjects" is formed largely according to the needs of construction companies that are customers of the labor market in the region. This means the variability nature of special "series of subjects" content depending on the enterprises demand for training specialists in civil engineering, which is secured in the variable part of the federal state educational standards of the professional education. However under the influence of economic factors the training requirements are constantly changing. Companies need specialists in different fields and specializations. That is why goals, curricula, training and methodological support of the educational process is constantly changing. Such variation in the content of education, its multi-variability and specialty, aiming, provided by the federal state educational standards by means of the variable part of training units, ensures flexibility. The most flexible and dynamic part of the curriculum-content of disciplines and internships. This part provides a rapid restructuring of the training content according to the regional features, taking into account the specifics of the relationship of educational organizations participating in the cluster along with enterprises. Flexibility training content allows taking into account the personal needs and interests of students, due to the components of the curriculum set by the institution and chosen by a student.

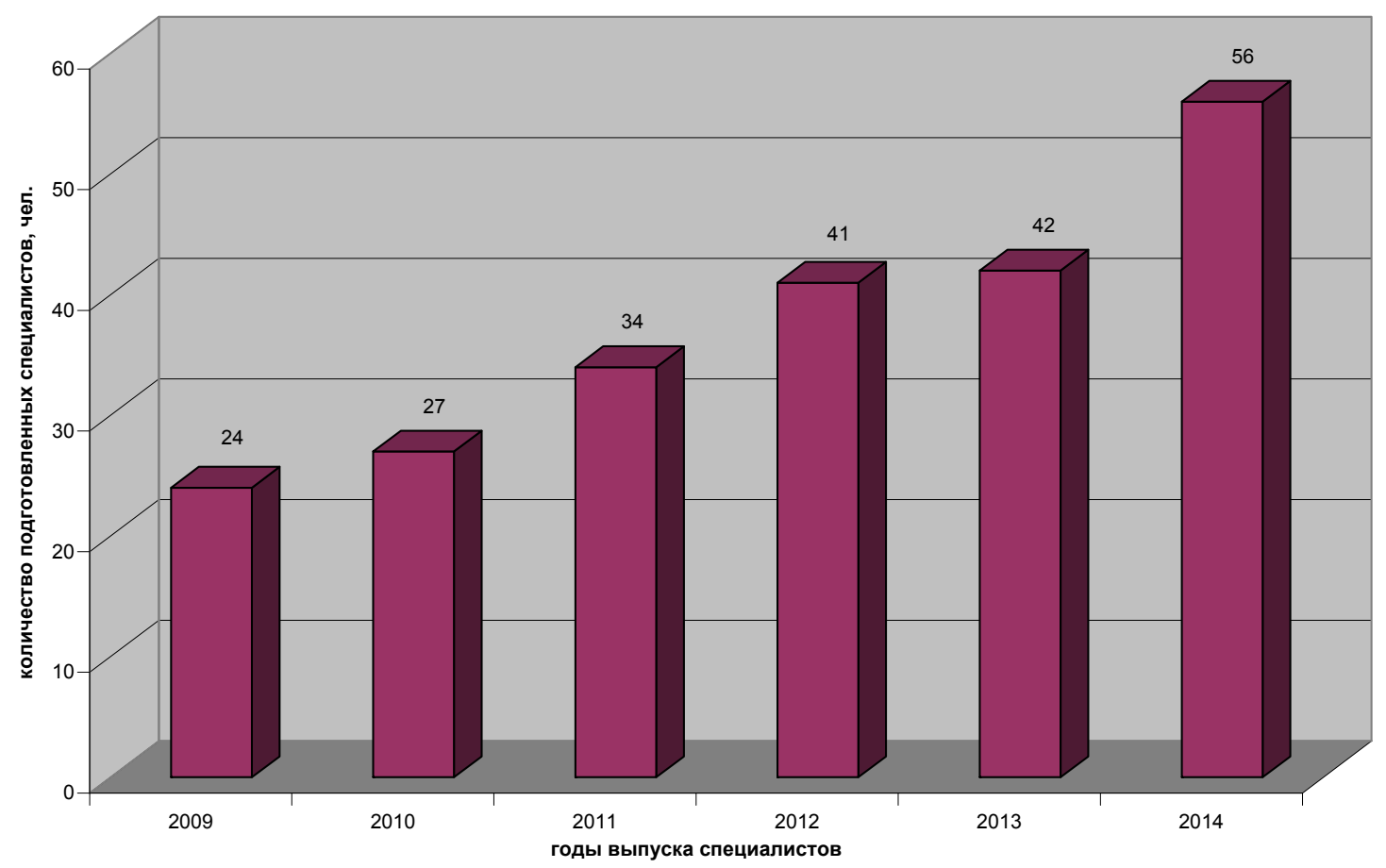

Figure 1. The number of graduates trained by coherent curricula 
Flexible content of training allowed abandoning cyclical (periodic) reconsideration of training documentation and come to the open method of its formation. By differentiation the educational process and the relationship of its components such openness makes it possible to create flexible organizational forms of training and receive a new quality of learning content. Thus, many of the changes in the curricula and programs are now being in the "self-regulation". The whole process of adjusting the content of training courses for specialization comes from particular company-customer (Biktagirova \& Valeeva, 2013). For example, the quality of construction works is determined by the level of training, knowledge of modern construction technologies and ability to use the devices, tools and equipment for the implementation of innovative technologies. Proper quality and performance cannot be achieved without acquisition of basic physical and technical properties of new building materials and the knowledge of complete systems and their professional use. In our days finishing materials of dry construction manufactured by german company "KNAUF" are widely used. However, their misuse leads to a crash in the operated facilities. One of the reasons for these accidents is the lack of skills. And, in order to expand the market of construction and finishing materials "KNAUF" company needs to increase the number of highly qualified specialists. Therefore, the concerns of "KNAUF" company include training Russian experts correct application of its products. To this end, on the basis of Kazan State University of Architecture and Engineering "KNAUF" has established modern educational-consulting center. Over the past 6 years this center has trained 1,162 specialists (Fig. 2).

At the Center all the educational cluster members are trained by modular programs that are created according to modern technologies of finishing works, using "KNAUF" company materials. During theoretical classes within the disciplines, chosen by the student within 34 hour unit (one credit unit), students get acquainted with: the nomenclature of the main finishing materials and components manufactured by "KNAUF" produced for complete finishing systems; modern finishing technologies essentials along with their application. At the workshops of 38 hours (one credit unit), during the training internships of one week duration (six credits) students master the rules of working with gypsum boards and elements of the frame, mounting technology ceiling structures and partitions. According to test results and workshops ( 0.5 credits) the certificate entitling to carry out works by the "KNAUF" company technology is given. The work of the "KNAUF" Training Center at Kazan State University of Architecture and Engineering is also important in terms of requirements of the federal state educational standards of higher education in the field of "Civil Engineering", which provide students with a worker specialty while studying at the university. To organize effective training worker specialties in the current state of affairs in the Russian high school is difficult due to the financial problems. In the context of education cluster this problem is perfectly solved. Thus, within the cluster on the basis of secondary vocational schools more than 200 students has mastered the specialties of bricklayer, plasterer, painter, electro-gas welder, mechanic and carpenter. This would undoubtedly improve the training quality and competitiveness of future civil engineers. The advantages of cluster organization of vocational education in comparison with the traditional organization lies in a more efficient use of internal resources, human resources, research and information capacity, finance, infrastructure, educational workshops and equipment, as well as in shortening the training terms by means of the integration of training content, implementation of continuity principle to aim, content, methods, forms, means of training. Cluster actually ensures the continuity of vocational training-from worker to engineer and scientist $(\mathrm{PhD}$.). But to really make these benefits work several conditions must be followed:

- The presence of highly qualified scientists and innovation capacity. The development of innovative capacity in the construction cluster allows to develop new building materials and adapt advanced construction and installation technologies to the construction industry;

- The presence of interaction between educational institutions within the cluster with construction industry in the region - thhis interaction takes the form of student teams, organizing and conducting field trips, participation of the construction industry representatives in the final governmental assessment committee of universities, etc .;

- Availability of professional education to the public at all levels, organization of continuing education possibility;

- Growth of public demand for the civil engineers and engineering education (for example, over a number of years at the Kazan State University of Architecture and Engineering a steady increase in the number of applicants, wishing to enter the University and having a high score of unified state exam). 


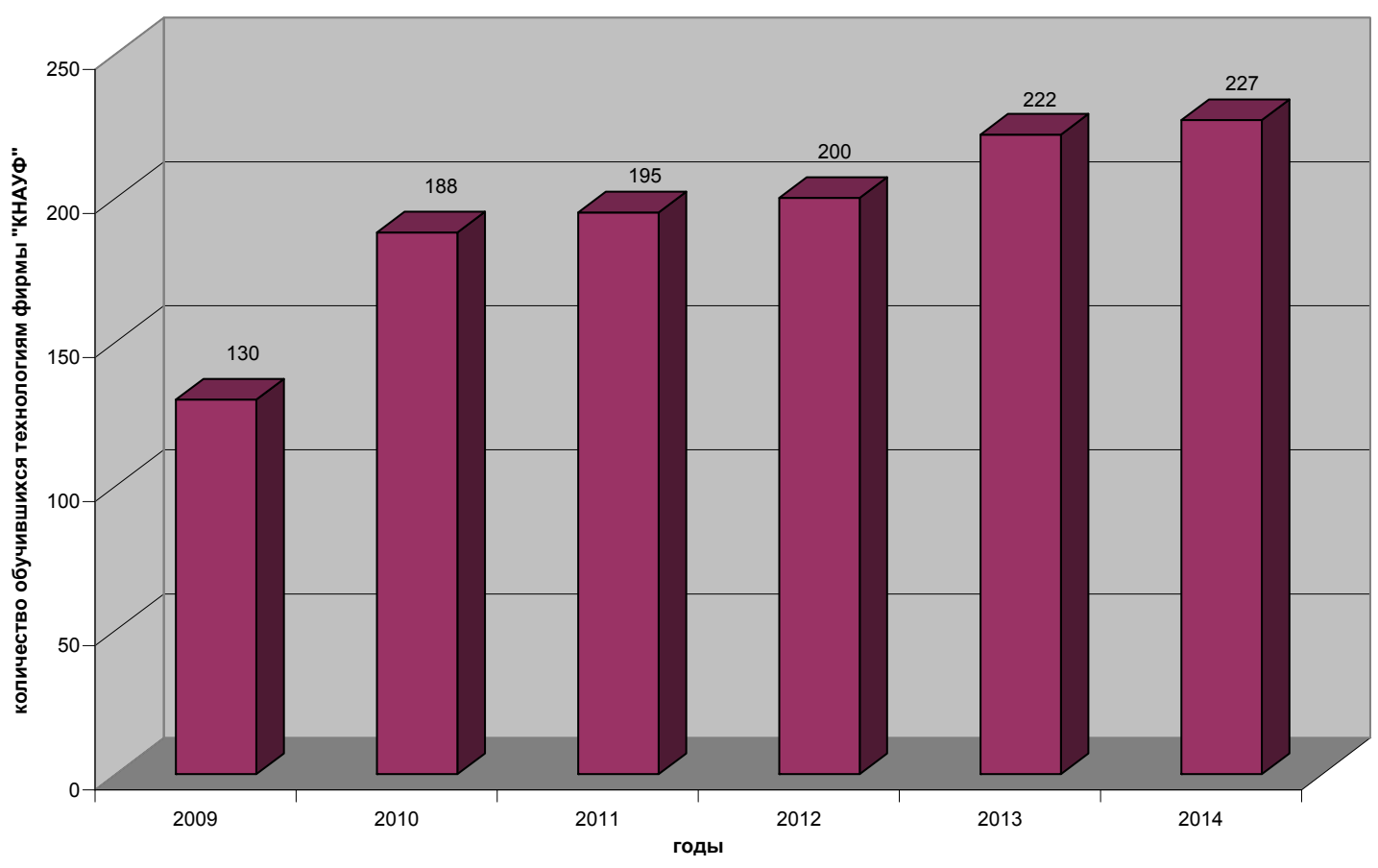

Figure 2. The number of future specialists, trained in Teaching and Consulting Center "KNAUF"

The above-mentioned advantages and conditions allow, in our view, to overcome the negative effects that have appeared in the Russian vocational education in the period of transition to a market economy:

- Lack of training quality and qualification of workers, specialists trained in educational institutions, the requirements of construction enterprises;

- Inability to obtain a labor profession by students of an engineering university;

- Inadequacy of educational research programs of universities and vocational schools to the needs of the construction industry of the region;

- Weak linkages between institutions of primary, secondary and higher education, research universities and businesses;

- Poor business climate, a low level of trust between construction companies, holding companies and firms and their pessimistic attitude to initiatives of regional authorities on the formation of educational cluster;

- Short-term goals of most firms and the lack of long-term business development strategies cause disbelief in positive socio-economic impact of the construction activities of the educational cluster since this impact is prolonged.

To overcome these disadvantages, education cluster development strategy is encouraged in which there are three factors. The first factor is economy. It lies in the creation of innovative, competitive system of vocational training, providing the successful development of the construction industry. The second factor is the social one. Where a guarantee for the employment of graduates in accordance with the received specialty is ensured. The third factor is pedagogics. It lies in collaboration of enterprises with educational institutions in education content designing, defining the set of required competences, organization of internships both for undergraduates and teachers, organization of further education of already qualified specialists, collaboration of several enterprises for the development of innovative production of building materials and technologies. Obviously, all three factors are interrelated and complementary. So, working together with construction firms to develop innovative construction projects, materials, technologies, designs and training of specialists with innovative thinking (pedagogical factor), and their employment (social factors) can significantly improve the economic efficiency of construction and the level of reliability of constructions. This provides a high level of competitiveness of construction products on the market (economic factor). 


\section{Discussions}

Theory of the discussions for the establishment and functioning of educational clusters was studied by Koretsky and Lapygin (2006), Muhametzyanova and Pugacheva (2007), Smirnov (2010), Shaidullina (2010), etc.

The formation of a professional competence for future specialists in educational cluster was studied by Zhuravleva (2011), Gavrilova (2011), Kadyrova (2013), etc.

Unlike the above-mentioned works, the process of training specialists in construction education cluster by the coherent curriculum was studied.

There are now quite a number of publications on educational clusters. A detailed discussion of these publications can be found in the work of Korchagin and Safin (2012). They deal with the definition of the education cluster, its main characteristics, structure and model educational clusters, etc., i.e. various organizational and pedagogical aspects of the establishment and functioning of the educational clusters. Nevertheless, the works, dealing with the experience of vocational training of students within the education cluster today, are not enough. However, this experience is valuable for both practical teachers and enterprises since everyone is interested in the search for means of improving the quality of vocational education. In order to fill this gap and to summarize the experience of professional training of students in the educational cluster by the example of the construction educational cluster we have written this article.

\section{Conclusion}

To summarize all we must point out that the establishment of educational cluster enabled:

- To implement, in the educational process, the principles of continuity of different educational levels and continuity of education obtainment in accordance with their capabilities and preferences;

- To improve the quality of training students to a level that meets modern requirements of the construction industry, and, at the same time, to optimize the cost of training for the construction industry by sharing all the logistics cluster, teaching methods, personnel and resource base of the educational cluster;

- To implement a public-private partnership between construction business and educational institutions within the cluster in the practical training of students, their employment, internship, further education of teachers, carrying out of joint studies and activities, the development of innovative building materials, products, structures and technologies.

In the current difficult socio-economic conditions in Russia, it is essential to ensure the effectiveness and competitiveness of construction industry specialists and the construction industry as a whole.

\section{References}

Aituganov, I. M., Korchagin, E. A., \& Safin, R .S. (2012). Practical training: The interaction of the university and enterprise. Higher education in Russia, 6, 163-166.

Biktagirova, G. F., \& Valeeva, R. A. (2013). Technological approach to the reflection development of future engineers. In 2013 International Conference on Interactive Collaborative Learning (pp. 427-432). ICL. http://dx.doi.org/10.1109/ICL.2013.6644615

Gavrilova, O. E. (2011). Formation of professional competence of students-The future experts in the conditions of garment production education cluster (Doctoral thesis). Kazan.

Ivanenko, N. A., Mustafina, G. M., Sagitova, V. R., Akhmetzyanov, I. G., Khazratova, F. V., Salakhova, I. T., \& Mokeyeva, E. V. (2015). Basic components of developing teachers' research competence as a condition to improve their competitiveness. Review of European Studies, 7(4), 221-227. http://dx.doi.org/10.5539/res.v7n4p221

Ivanenko, N. A., Burdukovskaya, E. A., Yunusova, A. B., Mukhametshina, R. F., Letyaev, V. A., Islamova, L. R., \& Yeremeyeva, T. S. (2015). Corporativity as a Condition for Developing Teaching Staff. Review of European Studies, 7(4), 49-53. http://dx.doi.org/10.5539/res.v7n4p49

Kadyrov, H. R. (2013). Variability of system design for multi-level training of machinery engineering companies in the region, based on an integrative approach (Doctoral thesis abstract). Kazan.

Korchagin, E. A., \& Safin, R. S. (2012). Educational Cluster: Interaction of high school and companies (p. 165).

Korchagin, E. A., \& Safin, R. S. (2013). Integration as the basis of the level professional education in the scientific-educational cluster. Higher education in Russia, 6, 19-25.

Koretsky, G. A., \& Lapygin, D. Y. (2006). Prerequisites of the integration into the educational cluster. Vladimir 
State University: E-journal. Retrieved from http://jornal/vlsu/ru/index/php?

Masalimova, A. R., Schepkina, N. K., Leifa, A. V., Burdukovskaya, E. A., \& Shaidullina, A. R. (2014). Mentoring perfection in modern enterprises conditions: Practical recommendations. American Journal of Applied Sciences, 11, 1152-1156. http://dx.doi.org/10.3844/ajassp.2014.1152.1156

Masalimova, A. R., \& Nigmatov, Z. G. (2015). Structural-Functional Model for Corporate Training of Specialists in Carrying Out Mentoring. Review of European Studies, 7(4), 39-48. http://dx.doi.org/10.5539/res.v7n4p39

Mukhametzyanova, G. V., \& Pugacheva, N. B. (2007). The cluster approach to the management of vocational education (p. 144). Kazan: IPP RAO.

Safin, R. S., Korchagin, E. A., Zagidullina, G. M., Vildanov, I. E., Sharafutdinov, D. K., \& Abitov, R. N. (2012). The integration process of the formation and development of civil engineering educational cluster. News of KSUAE, 4, 520-529.

Safin, R. S., Korchagin, E. A., Vildanov, I. E., Abitov, R. N., Sharafutdinov, D. K., Suchkova, T. V., \& Shkindereva, I. N. (2013). Scientific and methodological support of institutional interaction (state) and corporate professional education (p. 136).

Shaidullina, A. R., Ishmuradova, A. M., Maksimova, E. V., Yevgrafova, O. G., Derdizova, F. V., Baklanov, P. A., \& Bagateeva, A. O. (2015). The Implementation of the Cluster Approach in the Regional System of Vocational Education. Review of European Studies, 7(4), 66-72. http://dx.doi.org/10.5539/res.v7n4p66

Shaidullina, A. R., Masalimova, A. R., Vlasova, V. K., Lisitzina, T. V., Korzhanova, A. A., \& Tzekhanovich, O. M. (2014). Education, science and Manufacture Integration Models features in Continuous Professional Education System. Life Science Journal, 11(8s), 478-485.

Shaidullina, A. R., Morov, A. V., Morova, N. S., Petrova, T. N., Kirillova, O. V., Kirillova, T. V., \& Riazantzeva, I. M. (2015). The Features of Social Partnership as a Mechanism for the Integration of Education and Production. Review of European Studies, 7(3), 292-297. http://dx.doi.org/10.5539/res.v7n3p292

Shaidullina, A. R., Pavlova, N. A., Minsabirova, V. N., Burdukovskaya, E. A., Yunusova, A. B., Letyaev, V. A., \& Afanasev, A. S. (2015). Integration Processes in Education: Classification of Integration Types. Review of European Studies, 7(4), 27-31. http://dx.doi.org/10.5539/res.v7n4p27

Shaidullina, A. R., Sinitzyn, O. V., Nabiyeva, A. R., Yakovlev, S. A., Maksimov, I. N., Gatina, A. R., \& Akhmetov, L. G. (2015). Functions and Main Directions of Development of the Integrated Educational-Industrial Complex "College-University-Enterprise". Review of European Studies, 7(4), 228-233. http://dx.doi.org/10.5539/res.v7n4p228

Smirnov, A. V. (2010). Educational clusters and innovative teaching at the university (p. 92). Kazan: MES.

Zhuravleva, M. V. (2012). System of advanced professional training for the petrochemical complex: By the example of Republic of Tatarstan (Doctoral thesis). Kazan.

\section{Copyrights}

Copyright for this article is retained by the author(s), with first publication rights granted to the journal. This is an open-access article distributed under the terms and conditions of the Creative Commons Attribution license (http://creativecommons.org/licenses/by/3.0/). 